\title{
Characteristics of Functional Film Synthesized on the Cover Glass of Photovoltaic Modules
}

\author{
Seungcheol Yoo ${ }^{1, \dagger}$, Changyeon Lee ${ }^{1,+}$, Seokwon Lee ${ }^{1}$, Chulsoo Kim ${ }^{1}$, Wonseok Choi ${ }^{1, * \mathbb{C}}$, Young Park ${ }^{2}$, \\ Jung Hyun Kim ${ }^{3}$ (i) and Yeon-Ho Joung ${ }^{4}$
}

1 Department of Electrical Engineering, Hanbat National University, Daejeon 34158, Korea; aizimhk@naver.com (S.Y.); lcyo@naver.com (C.L.); dltjrdnjs000@naver.com (S.L.); msdkcs1@gmail.com (C.K.)

2 Department of Electrical System Engineering, Hanbat National University, Daejeon 34158, Korea; ypark@hanbat.ac.kr

3 Department of Advanced Materials Science and Engineering, Hanbat National University, Daejeon 34158, Korea; jhkim2011@hanbat.ac.kr

4 Department of Electronics Engineering, Hanbat National University, Daejeon 34158, Korea; yhjoung@hanbat.ac.kr

* Correspondence: wschoi@hanbat.ac.kr

+ Both authors contributed equally to this work.

check for

updates

Citation: Yoo, S.; Lee, C.; Lee, S.; Kim, C.; Choi, W.; Park, Y.; Kim, J.H.; Joung, Y.-H. Characteristics of

Functional Film Synthesized on the Cover Glass of Photovoltaic Modules. Energies 2021, 14, 6671.

https://doi.org/10.3390/en14206671

Academic Editors: Venizelos

Efthymiou and Christina

N. Papadimitriou

Received: 4 September 2021

Accepted: 12 October 2021

Published: 14 October 2021

Publisher's Note: MDPI stays neutral with regard to jurisdictional claims in published maps and institutional affiliations.

Copyright: (c) 2021 by the authors. Licensee MDPI, Basel, Switzerland. This article is an open access article distributed under the terms and conditions of the Creative Commons Attribution (CC BY) license (https:/ / creativecommons.org/licenses/by/ $4.0 /)$.

\begin{abstract}
In this study, the characteristics of functional films were investigated according to the number of coatings and their heat treatment times. The functional coating films were deposited on glass substrates made of the same material as the cover glass of photovoltaic (PV) modules. Each film was coated once by brushing with a special silica-based solution, and each heat treatment was done using a hot-air fan for $2 \mathrm{~min}$ at $300{ }^{\circ} \mathrm{C}$. The substrates were coated once, twice, and thrice, respectively, and were annealed once, twice, and thrice by drying and cooling alternately. The specimens were then analyzed for their anti-pollution properties, contact angles, light transmittance, and mechanical properties. The anti-pollution function was confirmed through a self-cleaning test, while the contact angle and light transmittance were examined using special equipment. Mechanical properties, including hardness and adhesion, were confirmed using the standard hardness testing method (ASTM D3363) such as those using an H-9H, F, HB, or B-6B pencil (Mitsubishi, Japan) and a standard adhesion testing method (ASTM D3359). It was confirmed that the film coated once yielded a very low contact angle of $8.9^{\circ}$ and very good anti-pollution properties. Its adhesion and strength also showed high values of $5 \mathrm{~B}$ and $9 \mathrm{H}$, respectively.
\end{abstract}

Keywords: functional film; anti-pollution; bar coating; hot-air annealing; photovoltaics module

\section{Introduction}

Solar energy is energy converted from the sun's radiation to the earth. It is the most environment-friendly renewable energy among all the renewable energies, including wind power, bio-energy, and stream power [1-3]. Photovoltaic (PV) modules, which are energy transformers, are supposed to be located outdoors to increase their direct exposure to sunlight. Pollutants like dust, yellow dust, animal excrements, or snow, however, can be easily deposited on the modules' surfaces and can cause malfunction or decrease in efficiency. It has been reported that these pollutants decrease power generation efficiency by approximately $9.5 \%[4,5]$.

Numerous researches on minimizing the effects of pollutants on PV modules have been carried out [6-9]. The most outstanding method developed so far is the photocatalyst coating technology, which is currently being used in solar cell operation. However, this technology has a weak point in terms of durability and it also requires additional photonic energy (Ultra Violet) to activate the catalytic action [9]. In relation to the coating film for PV modules, it needs a high transparency level to ensure light exposure. It also needs strong mechanical and chemical properties if it is to be used as the outermost layer of 
the PV modules $[10,11]$. Nowadays, it is hard to clean the pollutant by manual labor for a large-scaled solar power plant due to high maintenance expenses. Another cleaning approach is performed by a robot, which has issues in its high installation cost and frequent mechanical and electrical failures. Therefore, if the contaminants can be removed using effortless methods like water spray or rainfall, the economic efficiency of solar power generation can be significantly improved.

In this study, the possibility of more efficient and effortless methods has been studied with a functional coating process to demonstrate anti-pollutant and easy cleaning features. The coating process was performed with consideration for on-site processing to target enhanced power generation for planned and established solar power plants. Coating was done by bar coating and hot-air annealing using an air gun. It was done one to three times to show the mechanical and electrical characteristics of the film depending on the number of coatings. Also, comparing the different coating numbered film's characteristics will indicate the required processing for the anti-pollutant film. Natural drying and thermal annealing of the films were performed to show the film's electrical and mechanical characteristics based on the temperature effect. The possibility of easy cleaning of the film was performed by mimicking the water dropping condition.

\section{Experimental}

The glass substrates used in this experiment were the same low-iron tempered glass used for the cover glass of the PV modules. The $\mathrm{SiO}_{2}$-based coating material (FC-G703, Wellture FineTech, Daejeon, Korea) is a liquid solution consisting of water as a solvent and inorganic materials including $\mathrm{SiO}_{2}, \mathrm{Li}$, and $\mathrm{K}$. The solution's properties are 1-3 cP viscosity, $1.13 \pm 0.05$ specific gravity, $\mathrm{pH} 10-12,1.1 \mathrm{~g} / \mathrm{cm}^{3}$ density, and $100{ }^{\circ} \mathrm{C}$ boiling point $[12,13]$. The substrates were cleaned using an ultrasonic cleaning machine with trichloroethylene, acetone, methanol, and deionized water (DI water) for a total of $10 \mathrm{~min}$. Nitrogen gas was then used to dry all the substrates before bar coating them with the silica-based solution. The substrates were bar-coated one to three times, respectively as shown in Figure 1a. Then they were dried naturally for $10 \mathrm{~min}$ at room temperature. All the specimens underwent heat treatment one to three times using a hot-air fan (GHG 500-2, Bosch, Stuttgart, Germany) at above $300^{\circ} \mathrm{C}$ for $2 \mathrm{~min}$ as shown in Figure 1b. Cooling was done in a natural environment, with the same procedure for $10 \mathrm{~min}$.

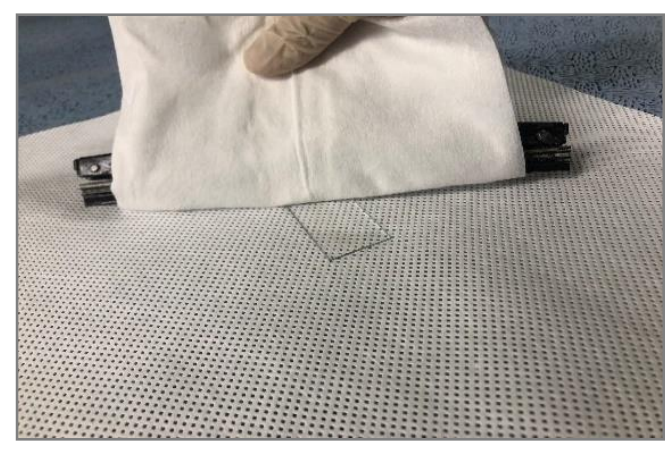

(a)

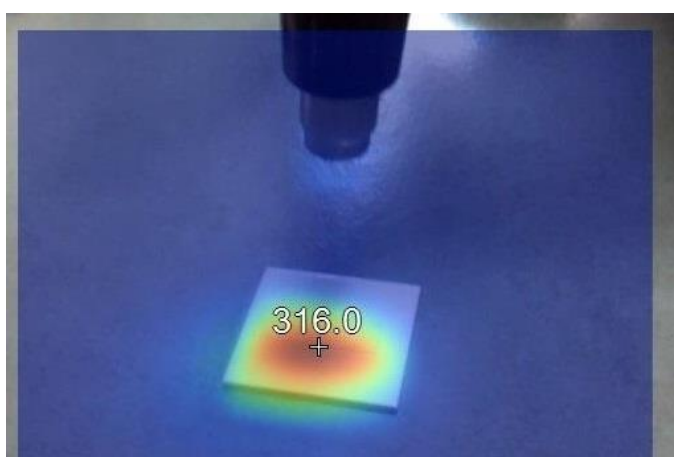

(b)

Figure 1. Process of the functional films used in this work: (a) bar coating, (b) hot-air fan annealing.

All the specimens' anti-pollution function, contact angle, light transmittance, and mechanical properties were then measured. A self-cleaning test was done by depositing different contaminants on the surface of the glasses, and cleaning them using waterdrops. The contact angles were measured using a contact angle analyzer (Phoenix 300 Auto, S.E.O.), while the light transmittance levels were examined via UV-visible spectroscopy (Mega-700, Scinco, Seoul, Korea). Hardness was measured using a hardness tester from CORE TECH, Korea, in accordance with ASTM D3363, which is the measurement method of the American Society for Testing Materials (ASTM). Adhesion was measured using the 
$\mathrm{H}-9 \mathrm{H}, \mathrm{F}, \mathrm{HB}$, and B-6B pencils from Mitsubishi in accordance with ASTM D3359, which is the surface adhesion measurement method of ASTM [13].

\section{Results and Discussion}

The coated film should have much better anti-pollution property to achieve high efficiency for PV modules. Figure 2 shows a mimicking experiment of an anti-pollution environment and the self-cleaning performance. Three different permanent markers (Name pen M, Monami, Seoul, Korea) with three different colors (red, blue, black) were used to scratch a circle shape on the coated films. The polluted surface of the PV module classes is simulated by coloring of the permanent markers. The surfaces of the films or the polluted markers were exposed by water dropping to simulate a rainy environment. After a 1-minute waiting time after water dropping, the substrate was shaken to spread the water, comprising the self-cleaning test.

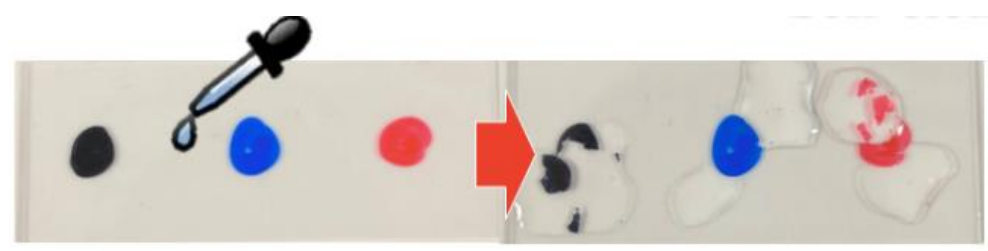

(a)

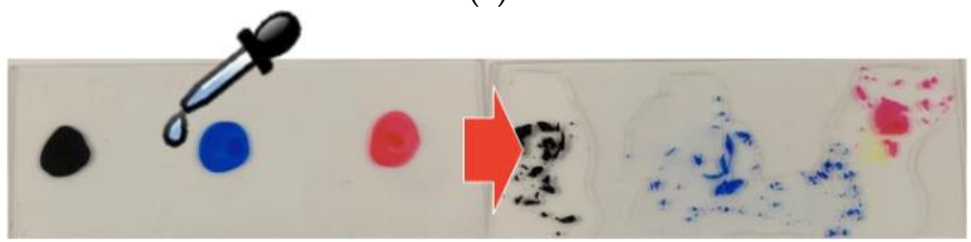

(b)

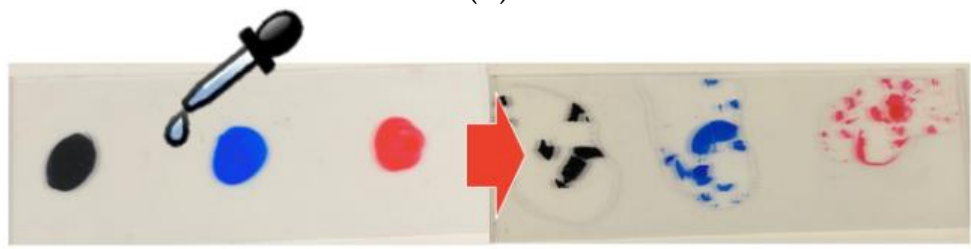

(c)

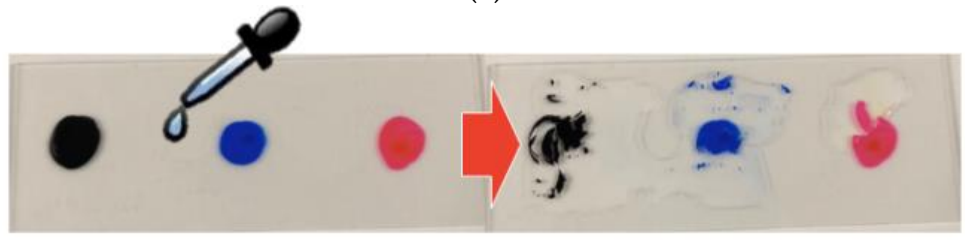

(d)

Figure 2. Anti-pollution characteristics according to the number of coating and annealing: (a) natural drying, (b) one step, (c) two steps, and (d) three steps.

The self-cleaning test showed strong anti-pollution characteristics in all the specimens, but the substrate cleaned with one-time coating exhibited the highest cleaning ability, followed by the substrates coated twice and thrice. The naturally dried specimen showed the lowest cleaning ability among all the specimens. The results are shown in Figure 2.

The contact angle of the substrate coated and annealed once also indicated the highest hydrophilicity with the smallest contact angle $\left(8.9^{\circ}\right)$. The two- and three-step-treated glasses also showed excellent hydrophilicity $\left(15^{\circ}\right.$ or less). The naturally dried glass had the largest contact angle, which also explains its lowest self-cleaning ability. Figure 3 shows the results of the contact angle measurements. 


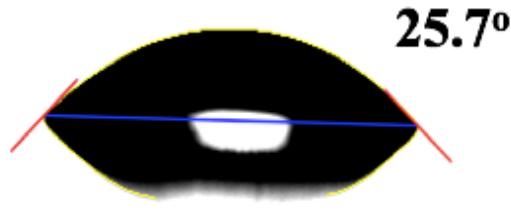

(a)

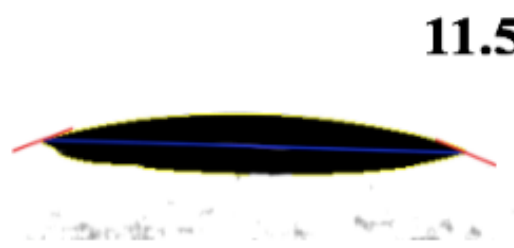

(c)

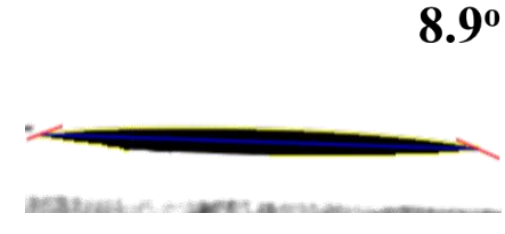

(b)

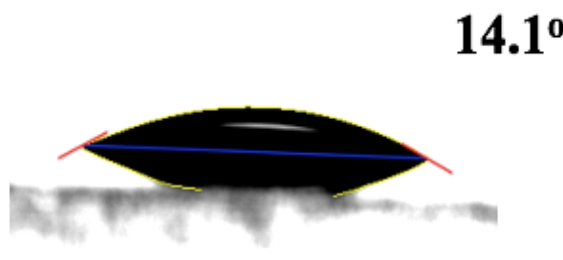

(d)

Figure 3. Contact angle characteristics according to the number of coating and annealing: (a) natural drying, (b) one step, (c) two steps, (d) three steps.

In Figure 4, all the substrates showed excellent transparency (around 90\%), with the one-time-treated substrate having the highest level of light transmittance $(99.8 \%)$. As the number of coating is increased, the light transmittance level became lower, but with a difference of around 1\%. The naturally dried substrate had the lowest light transmittance level (89.5\%).

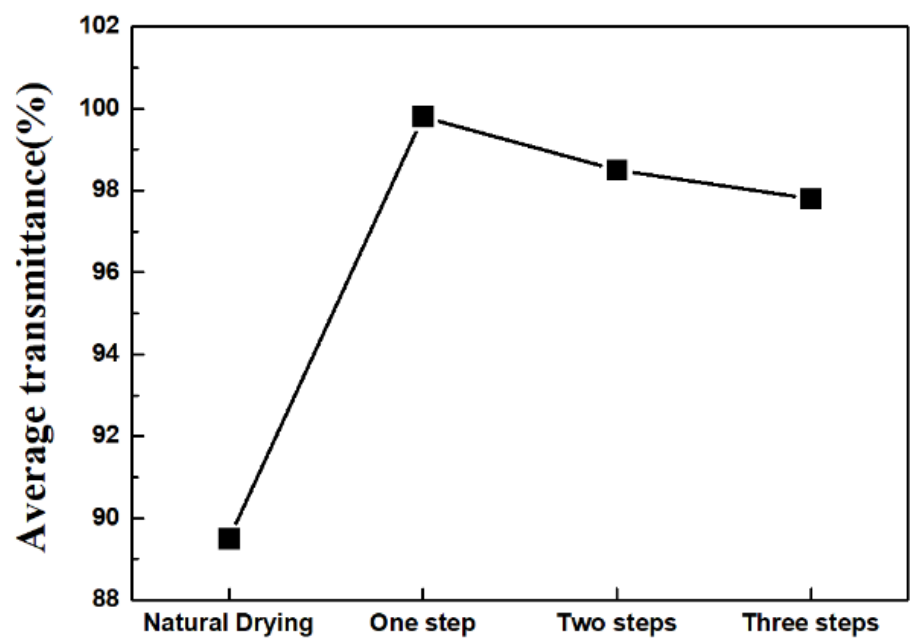

Figure 4. Average light transmittance of the substrates coated and annealed once, twice, and thrice.

The adhesion property of the films was tested using the ASTM D3359 procedure. The test was performed by making squares and counting the number of detaching squares. Adhesion of the films to the substrates is shown in Figure 5. The naturally annealed sample has $2 \mathrm{~B}$ adhesion property. The annealed samples with high temperature show adhesion property that is as good as 5B. Test results of the films' hardness, done using the ASTM D3363 procedure, are shown in Figure 6. The procedure was performed by scratching the surface of the films using a pencil. The surface status is checked by coloring of the pencil. Hardness of the films has the same characteristics as adhesion. All high temperature annealed samples have higher hardness $(9 \mathrm{H})$ than naturally annealed samples $(7 \mathrm{H})$. All the specimens endured the physical changes well. The hardness and adhesion test results indicated that the films have strong durability and excellent adhesion levels onto the glasses' surfaces, making them suitable for use as a coating layer for outdoor glass. 


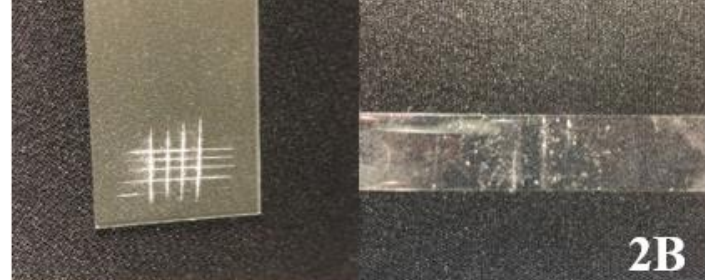

(a)

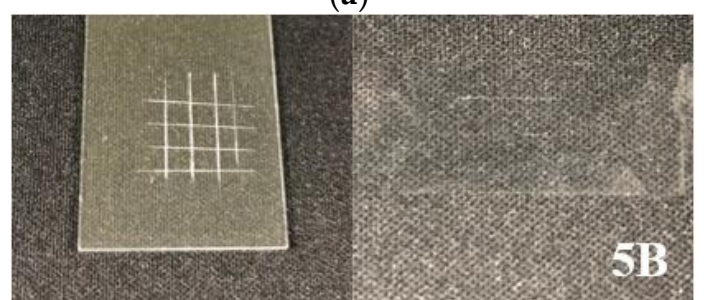

(c)

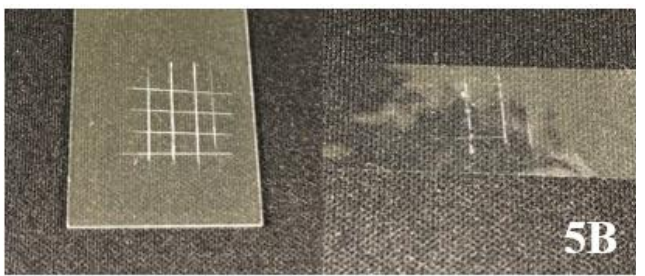

(b)

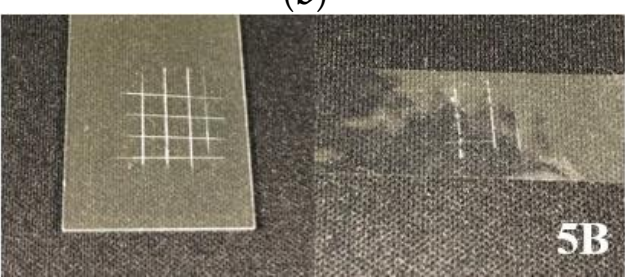

(d)

Figure 5. Adhesion characteristics according to the number of coating and annealing: (a) natural drying, (b) one step, (c) two steps, and (d) three steps.

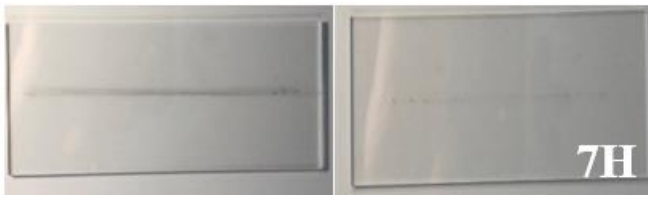

(a)

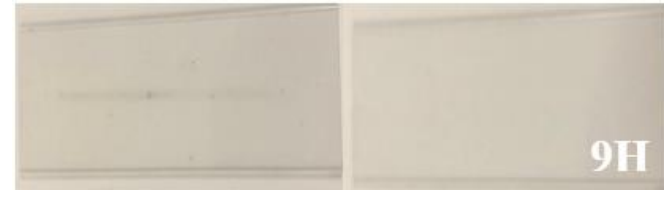

(c)

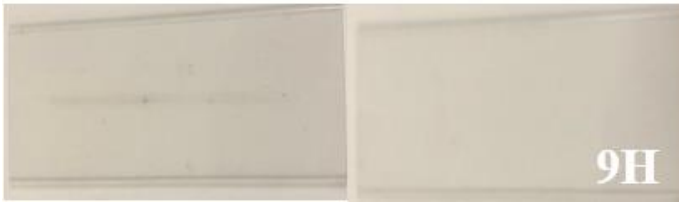

(b)

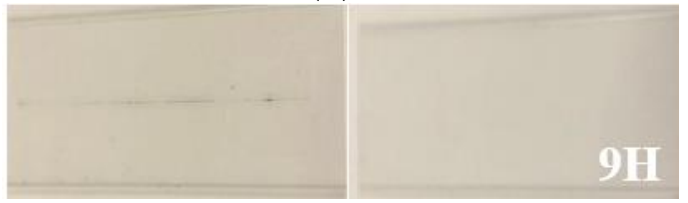

(d)

Figure 6. Hardness characteristics according to the number of coating and annealing: (a) natural drying, (b) one step, (c) two steps, and (d) three steps.

\section{Conclusions}

In this paper, we coated an anti-pollution film using a very simple and convenient process including bar coating and hot-air-fan annealing that can be applied on modules of installed and operational photovoltaic energy systems.

The one-time bar coating and hot-air-fan annealing method was observed to have the highest anti-pollution characteristics and smallest contact angle. Therefore, one-time coating and annealing is the most efficient method to make functional thin films for PV modules. Based on the experiment results, it can be concluded that the application of this process on the cover glass of PV modules will improve their anti-pollution characteristics. This will subsequently increase the power generation efficiency and economic efficiency of the PV module with its lower maintenance cost.

Author Contributions: Conceptualization, S.Y.; Data curation, C.L.; Formal analysis, S.L., C.K., Y.P., J.H.K., Y.-H.J.; Supervision, W.C. All authors have read and agreed to the published version of the manuscript.

Funding: This work was supported by the Korea Institute of Energy Technology Evaluation and Planning (KETEP) and the Ministry of Trade, Industry \& Energy (MOTIE) of the Republic of Korea (No. 20204030200080) with further support from Korea Electric Power Corporation. (Grant number: R17XA05-01).

Conflicts of Interest: The authors declare no conflict of interest. 


\section{References}

1. Tyagi, V.V.; Rahim, N.A.; Rahim, N.A.; Jeyraj, A.; Selvaraj, L. Progress in solar PV technology: Research and achievement. Renew. Sustain. Energy Rev. 2013, 20, 443-461. [CrossRef]

2. Kannan, N.; Vakeesan, D. Solar energy for future world-A review. Renew. Sustain. Energy Rev. 2016, 62, 1092-1105. [CrossRef]

3. Mekhilef, S.; Saidur, R.; Safari, A. A review on solar energy use in industries. Renew. Sustain. Energy Rev. 2011, 15, 1777-1790. [CrossRef]

4. Jaeberlin, H.; Graf, J.D.; Fachhochschule, B. Gradual Reduction of PV Generator Yield due to Pollution. In Proceedings of the 2nd World Conference on Photovoltaic Solar Energy Conversion, Vienna, Austria, 6-8 July 1998; pp. 1-4.

5. Elnozahy, A.; Rahman, A.K.A.; Ali, A.H.H.; Abdel-Salam, M.; Ookawara, S. Performance of a PV module integrated with standalone building in hot arid areas as enhanced by surface cooling and cleaning. Energy Build. 2015, 88, 100-109. [CrossRef]

6. He, G.; Zhou, C.; Li, Z. Review of Self-Cleaning Method for Solar Cell Array. Procedia Eng. 2011, 16, 640-645. [CrossRef]

7. Son, J.; Kundu, S.; Verma, L.K.; Sakhuja, M.; Danner, A.J.; Bhatia, C.S.; Yang, H. A practical superhydrophilic self-cleaning and antireflective surface for outdoor photovoltaic applications. Sol. Energy Mat. Sol. C 2012, 98, 46-51. [CrossRef]

8. Moharram, K.A.; Abd-Elhady, M.S.; Kandil, H.A.; El-Sherif, H. Influence of cleaning using water and surfactants on the performance of photovoltaic panels. Energy Convers. Manag. 2013, 68, 266-272. [CrossRef]

9. Arabatzis, I.; Todorova, N.; Fasaki, I.; Tsesmeli, C.; Peppas, A.; Li, W.X.; Zhao, Z. Photocatalytic, self-cleaning, antireflective coating for photovoltaic panels: Characterization and monitoring in real conditions. Sol. Energy 2018, 159, 251-259. [CrossRef]

10. Husain, A.A.F.; Hasan, W.Z.W.; Shafie, S.; Hamidon, M.N.; Pandey, S.S. A review of transparent solar photovoltaic technologies. Renew. Sustain. Energy Rev. 2017, 94, 779-791. [CrossRef]

11. Lee, K.; Um, H.-D.; Choi, D.; Park, J.; Kim, N.; Kim, H.; Seo, K. The Development of Transparent Photovoltaics. Cell Rep. Phys. Sci. 2020, 159, 251-259. [CrossRef]

12. Shan, B.; Kang, H.; Choi, W.; Kim, J.H. Characterization of a Functional Coating Film Synthesized on the Ceramic Substrate for Electrical Insulator Application According to Coating Method. Trans. Electr. Electron. Mater. 2017, 18, 148-150. [CrossRef]

13. Choi, W.S.; Lee, K.; Park, Y.; Joung, Y.-H.; Kwon, S.H.; Kim, J.H.; Kang, H. Effect of Annealing Temperature of the Functional Nano Thin Films Synthesized on a Ceramic Substrate. J. Nanosci. Nanotechnol. 2017, 17, 3289-3292. [CrossRef] 